\title{
Fungal Endophthalmitis
}

National Cancer Institute

\section{Source}

National Cancer Institute. Fungal Endophthalmitis. NCI Thesaurus. Code C53658.

Inflammation of the lining of the ocular cavities, which results from a fung al infection. 